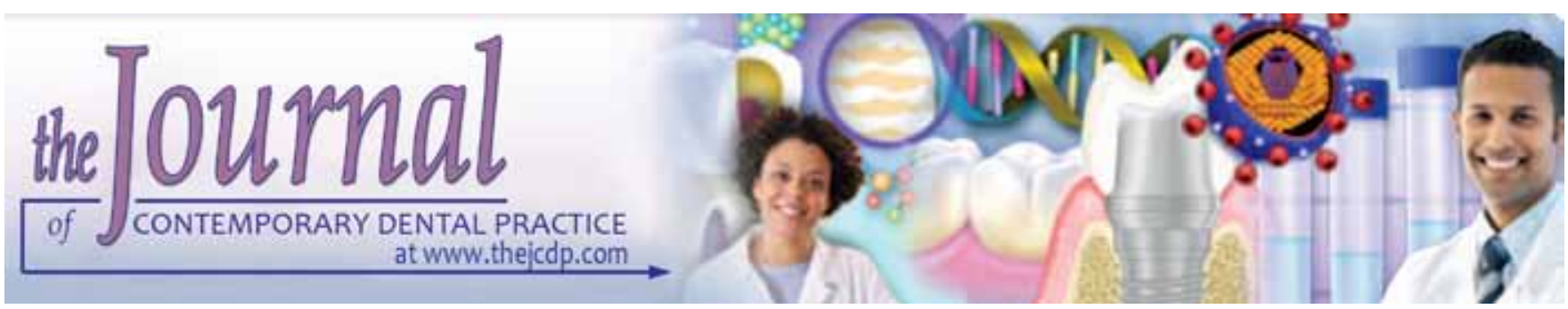

\title{
A Novel Approach for the Reimbursement of Permanent Partial Dental Disability Following Dental Injury
}

\author{
${ }^{1}$ Fouad Ayoub, ${ }^{2}$ Edgar Nehme, ${ }^{3}$ Sami Jad, ${ }^{4}$ Ziad Salameh
}

\begin{abstract}
Reimbursement of long-term permanent disability following a dental injury can lead to claims and legal involvement by the injured person. This will delay the treatment the patient's quality of life and the court system. A new formula has been hypothesized to address the problem. This might help the stakeholders including patients, insurance companies. The details of calculating the index and its significance are discussed. Implication studies are mandatory to refine the proposed hypothesis.
\end{abstract}

Keywords: Dental insurance, Dental injuries, Dental disability, Reimbursement.

How to cite this article: Ayoub F, Nehme E, Jad S, Salameh Z. A Novel Approach for the Reimbursement of Permanent Partial Dental Disability Following Dental Injury. J Contemp Dent Pract 2015;16(6):504-506.

\section{Source of support: Nil}

Conflict of interest: None

\section{INTRODUCTION}

Traumatic injuries to the orofacial region occurs frequently and comprise $5 \%$ of all injuries for which people seek treatment. ${ }^{1,2}$ Dental trauma has now become one of the most serious dental public health problem in children and adolescents. ${ }^{3}$ The need for treatment is usually as a direct

\footnotetext{
${ }^{1}$ Department of Basic Sciences, Faculty of Dental Medicine Lebanese University, Beirut, Lebanon

${ }^{2}$ Department of Oral Pathology, Faculty of Dental Medicine Saint-Joseph University, Beirut, Lebanon

${ }^{3}$ Department of Oral Surgery, Faculty of Dental Medicine Lebanese University, Beirut, Lebanon

${ }^{4}$ Department of Research, Faculty of Dental Medicine Lebanese University, Beirut, Lebanon

Corresponding Author: Ziad Salameh, Professor, Department of Research, Faculty of Dental Medicine, Lebanese University, Beirut, Lebanon, Phone: +961-71247147, e-mail: drzsalameh@gmail.com
}

result of facial injuries caused by direct impact following a car accident or after falling on the road/other places. ${ }^{4}$ These injuries vary from a simple teeth fracture to the jaw fractures and/or injury of the temporomandibular joints. ${ }^{5}$ Usually, dental treatment should be delivered shortly after the injury and delaying the treatment will complicate the treatment in terms of time and money. ${ }^{6}$

The multiple medical and dental insurance plans within region often lack a common set of definitions that are fundamental in interpreting and applying contract language. These entities may lack shared standards for processing claims and providing coverage information to the beneficiaries, practitioners and hospitals. ${ }^{7}$ In the past three decades, dental insurance has become a permanent fixture in the delivery of dental services. Some would argue that this has not been good for dentists. However, none will dispute that it is here to stay and that dentists must make some very important decisions in their practices with regards to dental insurance. ${ }^{8}$

After an accident causing damage, the injured party commonly undertakes the required treatment at the expense of the person who caused the injury or his/her insurance company. However, the loss of function and the long-term partial disability become subsequently imperative and a hard debate in addition to claim can initiate between the injured person and the insurance company. ${ }^{9}$ Resolving both issues immediately after the injury would save time, funds, provide reassurance to the offended person and save potential proceedings. As few years after the initial injury, patient can lose the damaged part (i.e. tooth) that may re-initiate claims against the insurance company from the injured party even after the first settling of the insurance due; this may impact the court daily work by increasing the number of claims especially in certain area of the world. Multiple individuals may be involved in making reimbursement decisions, reducing the likelihood of consistency across plans. ${ }^{10}$ 
The objective of this article was to derive a simplified method of calculating the insurance coverage decisions that could be portrayed to the long-term effects of the injury shortly after the event.

\section{METHODS}

Ayoub's formula was developed by the author to evaluate the imbursement value of the long-term effects of the injury shortly after the event. It is an original process to calculate the expenses of the permanent partial disability subsequent to injury making earlier the resolution of the procedure. It is a certified formula authorized for all dentists in their private practice, which can be gratified for this legal process. ${ }^{11}$ The calculation will be the estimation of the teeth problems that could arise after several years after initial treatment; the formula is thus used rather than coming up the 5 years to reconcile.

The formula is the following:

$$
X=\frac{[\mathrm{A}-(\mathrm{B}+\mathrm{C})] \times \mathrm{Y}}{\mathrm{A}}
$$

$X=$ Percentage of the permanent partial disability based on future estimation.

$\mathrm{A}=$ The life expectancy by gender in the country where the injury occurs.

$\mathrm{B}=$ The actual age of the injured person (at the time of injury).

$\mathrm{C}=$ The year number of normal function expected from injury.

$\mathrm{Y}=$ The percentage of permanent partial disability for this particular injury in the country of the injury.

\section{A Scenario}

A 18-year-old Lebanese male reported with an injury (fracture) of a central incisor tooth \# 11 , or 21 , or \#8 or \#9 $(\mathrm{B}=18)$. It is estimated that the patient could keep a normal function with his tooth for the next 3 years before extraction $(C=3)$. The life expectancy of a Lebanese male is 70 years $(\mathrm{A}=70)$; the compensation rate for the permanent loss of a tooth is $2 \%$ is there any monetary value attached to percentage? If not, it should have otherwise it would be difficult perception by readership $(\mathrm{Y}=2 \%)$. Using the formula, the partial permanent disability will be:

$$
X=\frac{[70-(18+3)] \times 2 \%}{70}=1.4 \%
$$

\section{DISCUSSION}

Traumatic injuries of the orofacial region constitute a significant clinical health problem. ${ }^{12}$ It might lead to the displacement or loss of teeth as well as medical, esthetic, functional and psychological problems. ${ }^{13}$ These injuries and their sequelae often require advanced treatment, and imply very high costs for patients insurance companies, and public health services. ${ }^{14,15}$

The structure of dental insurance is a major contributing factor in the implementation on any value-based plan. ${ }^{16}$ Variations in service coverage among dental insurance plans also complicate matters. This can create a conflict between the realities of the dental reimbursement system and the very few clinical practice guidelines that do exist. ${ }^{17}$ A lack of clear strategies to compensate for the short or long-term disability after dental injuries that could occur consequent an accident put the dentist and insurance companies in dilemma. Hence a simplified method to address this issue is essential to deliver immediate and appropriate care to individuals who encounter traumatic injuries.

In this context the formula, which has been developed by the author, will give a quick assessment of the immediate and long-term permanent disability index, which can be used as a guideline to manage the case. This will help to reduce claims and conflict with the insurance company after permanent disability following the initial injury; that will reduce the pressure at the court of claims reducing the total cost of treatment. ${ }^{18}$ Hence, this system will benefit for the patient as well as the insurance company and the court system. Implementation of the formula in various clinical scenarios is mandatory to refine and identify any loopholes. This formula can be applied in different medical scenarios involving trauma and injuries (i.e. orthopedics and traumatology) that may lead to permanent disability. Hence, further studies are mandatory to validate the formula.

\section{CONCLUSION}

The novel formula that is presented highlights the possibility to derive a quick and easy method for calculation of insurance compensation to orofacial injuries for permanent disability. Further improvements can be done based the implementation of the system and its outcome.

\section{REFERENCES}

1. Bastone EB, Freer TJ, McNamara JR. Epidemiology of dental trauma: a review of the literature. Aust Dent J 2000;45(1):2-9.

2. Glendor U. Aetiology and risk factors related to traumatic dental injuries: a review of the literature. Dental Traumatol 2009;25(1):19-31.

3. Cortes M, Marcenes W, Sheiham A. Prevalence and correlates of traumatic injuries to the permanent teeth of schoolchildren aged 9 to 14 years in Belo Horizonte, Brazil. Dental Traumatol 2001;17(1):22-26. 
4. Patel PB, Stanton DC, Granquist EJ. Common dental and orofacial trauma: evaluation and management. Med Clin North Am 2014;98(6):1261-1279.

5. Oberman B, Setabutr D, Goldenberg D. Traumatic dislocation of intact mandibular condyle into middle cranial fossa. Am J Otolaryngol 2014;35(2):251-253.

6. Craig PJ, Clement JG. The dentist's responsibilities with respect to a nofault motor accident compensation scheme. J Forensic Odontostomatol 2012;30 (Suppl 1) 40-46.

7. White BA, Monopoli MP. Issues regarding insurance and other third-party reimbursement for behavioral management procedures. Pediatr Dent 2004;26(2):137-142.

8. Inge R. The ins and outs of dental insurance. J Am Dent Assoc 2005;136(2):204-209.

9. Sleamaker TF. Successful third party management in the dental practice. Quintessence Int 1985;16(3):235-239.

10. Miranda GE, Siqueira MC, Ferreira RL, Delwing F, Daruge Junior E. Administrative and clinical denials by a large dental insurance provider. Braz Oral Res 2015;29(1).

11. Ayoub F, Nehme E, Jad S. A formula for the calculation of permanent partial disability payments after injury based on future estimation (Ayoub's Formula)', LB Copy right certificate of literary work 1939, 2001 June 02, 2001.
12. Andreasen JO, Andreasen FM, Andersson L. Textbook and color atlas of traumatic injuries to the teeth: John Wiley and Sons; 2013.

13. Ilma de Souza Cortes M, Marcenes W, Sheiham A. Impact of traumatic injuries to the permanent teeth on the oral health-related quality of life in 12 to 14-year-old children. Community Dentist Oral Epidemiol 2002;30(3):193-198.

14. Borum MK, Andreasen JO. Therapeutic and economic implications of traumatic dental injuries in Denmark: an estimate based on 7549 patients treated at a major trauma centre. Int J Paediat Dentist 2001;11(4):249-258.

15. Wong FS, Kolokotsa K. The cost of treating children and adolescents with injuries to their permanent incisors at a dental hospital in the United Kingdom. Dent Traumatol 2004; 20(6):327-333.

16. Sloane T. A new definition of transparency. Pricing, sparse quality data are not enough to fix the problems they aim to solve. Modern Healthcare 2007;37(26):56.

17. Voinea-Griffin A, Fellows JL, Rindal DB, Barasch A, Gilbert $\mathrm{GH}$, Safford MM. Pay for performance: will dentistry follow? BMC Oral Health 2010;10(1):9.

18. Audet A-MJ, Doty MM, Shamasdin J, Schoenbaum SC. Measure, learn, and improve: physicians' involvement in quality improvement. Health Affairs 2005;24(3):843-853. 